\title{
CYP450 and Its Implications in the Clinical Use of Antipsychotic Drugs
}

Fernando Mora' ${ }^{1}$, Juan D Molina ${ }^{2}$, Elena Zubillaga ${ }^{3}$, Francisco López-Muñoz ${ }^{4,5,6}$ and Cecilio Álamo ${ }^{7}$

${ }^{1}$ Psychiatry Service Infanta Leonor University Hospital, Madrid, Spain

${ }^{2}$ Short term Hospitalization Unit, Dr. Rodríguez Lafora Hospital, Madrid, Spain

${ }^{3}$ Medical Department, Janssen, Spain

${ }^{4}$ Chair of Genomic Medicine and Faculty of Health Sciences, Camilo José Cela University, Madrid, Spain

${ }^{5}$ Department of Pharmacology, Faculty of Medicine, University of Alcalá, Madrid, Spain

${ }^{6}$ Neuropsychopharmacology Unit, "Hospital 12 de Octubre" Research Institute, Madrid, Spain

${ }^{7}$ Department of Pharmacology Faculty of Medicine, University of Alcalá, Madrid, Spain

\begin{abstract}
Polypharmacy implies a high potential for drug-drug interactions. The capacity of the cytochrome P450 enzyme system involved in the metabolism of psychoactive drugs differs greatly, which leads to variable drug elimination rates and inter-subject differences in serum drug concentrations. Polymorphisms in genes coding for CYP450 enzymes contribute to this inter-subject variability. Therapeutic response and adverse effects vary among patients treated with the same dose of a certain drug. Polypharmacy, comorbidity and the use of certain substances (grapefruit juice, caffeine and tobacco) increase the chances of clinically relevant interactions in a psychotic patient. Choosing drugs with low interaction potential seems to be the best strategy to prevent clinically relevant interactions particularly in elderly, polymedicated, oncologic and HIV patients.
\end{abstract}

Keywords: CYP450; Drug interactions; Antipsychotic; Pharmacokinetic; Polypharmacy

\section{Introduction}

Drug-drug interactions (DDIs) are very common in clinical practice and are responsible for substantial increase in patient's morbidity and mortality. Globally drug-drug interactions are responsible for approximately $20 \%$ to $30 \%$ of notified adverse reactions [1,2]. It has been estimated that the risk for drug-drug interactions increases substantially to about $84 \%$ when the number of concomitants drugs rise from 2 to 6 agents [1]. In addition, it is known that there is a great variability between individuals, and therefore, drug-drug interactions are not always easy to recognize $[3,4]$.

Drug concentration at the site of action is regulated by absorption, distribution, metabolism, and excretion. Therefore, all these processes are keys to the pharmacologic action as well as the therapeutic efficacy and safety. A drug with unfavorable pharmacokinetic properties may result in an inadequate or inconsistent response, which may put the therapeutic use at risk. In addition, pharmacokinetics of a drug is usually a key factor for the appearance or absence of toxic effects, and as a result, it has a direct impact on the safety of treatment [5].

Drug-drug interactions resulting from absorption, distribution, metabolism, or elimination, as well as pharmacodynamic factors, are present for many common psychoactive medications. DDIs can negatively impact patient outcomes and can also have serious implications on the cost and quality of treatment. DDIs may be the cause of adverse drug reactions (ADRs) that put at risk the outcomes of therapy and the adherence to treatment $[6,7]$.

The potential for DDIs is particularly increased in the elderly due to polytherapy. In fact, polypharmacy increases the complexity of therapeutic management, and therefore, the risk of clinically relevant DDIs, which can both induce the development of ADRs or reduce the clinical efficacy. The challenge presented by adverse DDIs in clinical psychiatry will continue to expand as the complexity of medication regimens increase in a population that receive more sophisticated and diverse psychotropic agents [8,9]. Most individuals with schizophrenia take medications indefinitely and at some point take additional medications. Therefore, the risk of polypharmacy-related complications is real in this population as well as the risk of reduced adherence to treatment $[6,7]$.
The aim of the present article is to review and update common drug-drug interactions and its implications in the clinical use of antipsychotic drugs with a special focus on interactions associated to CYP450 enzymes (CYP's) activity.

\section{Drug-drug interactions}

The two main types of DDIs are pharmacodynamic and pharmacokinetic interactions.

Pharmacodynamic interactions: In a pharmacodynamics interaction, two drugs have synergistic or antagonistic effects, without changes in their pharmacokinetic profile. There are many examples of pharmacodynamic interactions with antipsychotics.

Thus, some antipsychotics with anticholinergic properties, as clozapine, chlorpromazine and trifluoperazine, can cause constipation. The association of these agents with opioids, for example codeine, increased the constipation. Furthermore, the synergistic anticholinergic effect of drugs, such as antiparkinsonian agents, can increase the anticholinergic effects of these antipsychotics, leading to dry mouth, blurred vision, and possibly delirium [10].

Potential pharmacodynamic interactions can be present with addition of many other drugs to antipsychotics. This includes all sedative drugs, as benzodiazepines, antihistaminics, some antidepressants, increasing the risk of sedation. On the other hand, pro-convulsant drugs added to atypical antipsychotics, especially clozapine and olanzapine can increase the risk of seizures $[11,12]$.

Many antihypertensives in association with antipsychotic drugs

*Corresponding author: Juan de Dios Molina, Short term Hospitalization Unit, Dr. Rodríguez Lafora Hospital, Ctra de Colmenar Viejo, Madrid-28049, Spain, Tel: +34 9158675 00; E-mail: jmolinamar@hotmail.com

Received: April 15, 2015; Accepted: May 12, 2015; Published: May 25, 2015

Citation: Mora F, Molina JD, Zubillaga E, López-Muñoz F, Álamo C (2015) CYP450 and Its Implications in the Clinical Use of Antipsychotic Drugs. Clin Exp Pharmacol 5: 176. doi:10.4172/2161-1459.1000176

Copyright: ( 2015 Mora $\mathrm{F}$ et al. This is an open-access article distributed under the terms of the Creative Commons Attribution License, which permits unrestricted use, distribution, and reproduction in any medium, provided the original author and source are credited. 
may increase the risk of falls and postural hypotension. Furthermore, a pharmacodynamic drug interaction may be the result of combining two or more drugs with established risk of prolongation of corrected QT interval (QTc), such as chlorpromazine and haloperidol $[11,13]$. The association of haloperidol with amiodarone or ondansetron can also induce a prolongation of QTc interval [14].

On other occasions, the association of an antipsychotic with other drugs can have an antagonistic effect, leading to treatment failure and a risk of relapse. An example of this may occur when combining antipsychotics with dopaminergic drugs for Parkinsonism, e.g., levodopa or dopaminergic receptors agonists. The result may be worsening motor function, a relapse of psychosis or a combination of both [10].

Pharmacokinetic interactions: Pharmacokinetic interactions may occur through various mechanisms, including alterations in drug absorption, distribution, metabolism, and excretion. The alteration of any of these processes may be associated with treatment failure or toxicity. Pharmacokinetic DDIs are usually identified by controlling the patient's clinical symptoms as well as the changes in serum drug concentrations.

For example, quetiapine pharmacokinetics is affected by concomitant administration of ketoconazole and carbamazepine, drugs that strongly modulate the activity of CYP3A4. Another example are the pharmacokinetic interactions between smoking and drugs that are CYP1A2 substrates, such as clozapine, and olanzapine [15,16].

Typically, pharmacodynamic DDIs can be anticipated by drug's mechanism of action and receptor occupancies, and these interactions can often be predicted and prevented. However, pharmacokinetic DDIs are much more difficult to anticipate. Knowing how a drug exerts its therapeutic effect rarely gives any information of its kinetic parameters or of the ways the drug may affect the metabolism of another agent $[8,9]$.

\section{Metabolic pathways for psychoactive drugs}

Metabolism can be an important determinant of the therapeutic activity, the interactions and the toxicity of psychoactive drugs. The common pattern of psychoactive drug metabolism is biphasic and consists of stepwise biotransformation and synthesis reactions. The major enzymatic reactions of drug metabolism are oxidation, reduction, and hydrolysis. These reactions are biotransformation reactions while conjugation is a synthesis reaction. A psychotropic drug may have a chemical structure suitable for biotransformation via one or more of these reactions.

Phase 1 (biotransformation) consists of the oxidation (hydroxylation), hydrolysis, or reduction of a lipid-soluble or nonpolar drug. The phase 1 enzymatic mechanisms most relevant to metabolism of psychoactive drugs are oxidation, reduction, and hydrolysis. CYP's enzymes are responsible for most phase I reactions $[6,17]$. CYP's will be described in more detail in the next section.

Phase 2 (synthesis) consists of the conjugation of a drug or its metabolite with an endogenous compound, mostly glycine, sulfate, or glucuronic acid. The result of either phase of metabolism is the production of metabolites that are generally more polar than the parent drug and are more readily excreted in the bile or urine. Both phases of biotransformation are the result of drug interaction with enzymes present in plasma, cytoplasm, mitochondria, and endoplasmic reticulum.
The most prominent phase 2 enzymatic family is the uridine 5'-diphosphate glucuronosyl-transferases (UGTs). UGTs are identified by a nomenclature system ( $1 \mathrm{~A} 1,1 \mathrm{~A} 4,2 \mathrm{~B} 7,2 \mathrm{~B} 15$, etc.), and each enzyme has a unique range of substrates, inhibitors, and inducers. The metabolism of some psychoactive agents like olanzapine, lamotrigine, and certain narcotic agents, is performed primarily by the UGTs. Thus, an understanding of UGT metabolism is important to anticipate and prevent drug-drug interactions concerning these isozymes $[3,18]$.

P-glycoprotein (P-gp) transporter is another important protein in metabolism of psychotropic drugs. P-gp is an ATP-dependent, extruding transporter. It resides in the plasma membrane of enterocytes of intestinal epithelium, and in this location regulates drug absorption. Like the P450 and UGT metabolic systems, the P-gp transporter has substrates, inhibitors, and inducers. P-gp is found in liver cells, in the cells of proximal renal tubules and in the capillaries of the blood-brain barrier, where it is one of the main elements that prevent substances entering to the CNS. Frequently, P-gp substrates, inhibitors and inducers have also involved with P450 system, and therefore it is not easy to discriminate the relative contribution of each metabolic system to a determined interaction or clinical effect $[19,20]$.

\section{The cytochrome P450 (CYP) system}

It is necessary to take into account the cytochrome P450 system when pharmacokinetic interactions are considered. Cytochrome P450 system is a superfamily of enzymes found mainly in the liver, are implicated in the metabolism of many drugs and have been shown to be involved in numerous interactions between drugs and foods, beverages, herbs and other medications [3,21].

Cytochrome P450 enzymes (CYP's) are responsible for the oxidative metabolism of a wide variety of both exogenous and endogenous compounds. The CYP's are a group of isoenzymes located primarily in the endoplasmic reticulum of hepatic cells. Drug metabolism by CYP's takes place primarily in the liver, but CYP enzymes are also found in many other tissues, including central nervous system (CNS) $[6,15,18,22]$.

CYP is an important superfamily of metabolizing enzymes, which are ubiquitously distributed in humans. The term 'cytochrome P450' was coined because of its spectral properties. In cytochrome P450, cytochrome stands for a hemoprotein, $P$ for pigment and 450 reflects the absorption peak at $450 \mathrm{~nm}$. Most of the CYP's are found in the endoplasmic reticulum, and some are localized mainly in mitochondria. The CYP's are involved in the metabolism of a broad variety of xenobiotics (drugs and chemical compounds which are foreign to the living organism) as well as endobiotics (endogenous compounds, including eicosanoids, cholesterol, hormones, and steroids) [23,24].

CYP genes have been described in 85 eukaryote (including vertebrates, invertebrates, fungi, and plants) and 20 prokaryote species. Of 74 gene families, 14 families exist in mammals. These 14 families comprise 26 mammalian subfamilies, of which more than 20 have been mapped in the human genome. Currently, in humans 57 different CYP genes (and more than 50 pseudogenes) are recognized, which are classified according to sequence homology into 18 families [23,25,26].

In 1966, Sladek and Mannering [27] demonstrated for the first time the presence of multiple forms of CYP's in liver microsomes. Further studies showed that phenobarbital inducible isoforms were different from the other inducible isoenzymes of CYP. Additional purification and characterization studies in following years demonstrated that many different forms of CYP's exist in the liver which has narrow 
but overlapping substrate specificities [28,29]. Figure 1 shows the distribution of the major CYP drug-metabolizing enzymes in the human liver [30].

To bring uniformity to CYP's classification, Nelson and colleagues proposed a nomenclature system in 1996 [26]. Based on amino acid sequence homologies, the CYP superfamily has been categorized into several families and subfamilies. Sequences that are $40 \%$ or more identical at the amino acid level belong to the same Family (designated by Arabic number). Sequences that are $60 \%$ or more identical belong to the same Subfamily, designated by a capital letter, and after this the individual genes are arbitrarily numbered (Table 1). It was recommended the root symbol 'CYP' for human, in contrast to 'Cyp' for mouse and Drosophila. Usually, the convention is to italicize the name when referring to the gene. For example, CYP2D6 is the gene that encodes the enzyme CYP2D6 [31].

In humans, the CYP superfamily is classified into 18 families and 57 subfamilies. Members of families CYP1, CYP2 and CYP3 primarily metabolize xenobiotics, such as drugs and environmentally derived compounds, and certain endogenous substrates. The CYP2 family metabolizes a large proportion of CNS-acting psychopharmacological drugs, such as antidepressants and antipsychotics; drugs of abuse, such as amphetamine and ethanol; and some endogenous neurochemicals, such as dopamine and serotonin.

\section{Polymorphisms and factors that influence CYP levels}

The levels of CYP forms in plasma, brain, liver and other tissues vary widely among individuals. This can be caused by factors that affect CYP expression levels, including genetic polymorphisms, which can result in differences in the plasma levels of drugs and their metabolites. For example, there is substantial variation in the amount and function of CYP2D6 enzyme between individuals. CYP2D6 has the largest phenotypical variability among the CYP's, mostly because of genetic polymorphism. The different alleles may show normal, reduced, and non-existent CYP2D6 function in different individuals [32,33].

Ethnic groups may show different patterns of CYP metabolization.

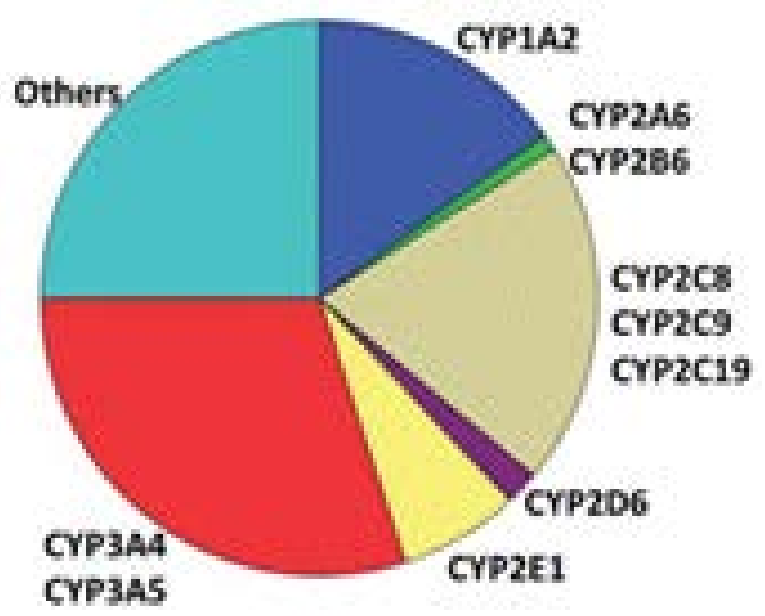

Figure 1: Distribution of the main CYP drug-metabolizing enzymes in the liver. CYP3A4 is the major form of CYP's in the adult liver and metabolizes the greatest proportions of drugs. Although CYP2D6 represents approximately only $2 \%$ of the liver CYP content, it plays an important role in drug metabolism particularly in clinical psychopharmacology [30].
For example, about $10 \%$ of white people have mutated alleles in their CYP2D6 that result in a functionally deficient CYP2D6 enzyme. These patients are known as poor metabolizers and often respond inadequately to psychotropic agents that are activated by CYP2D6. An ultrarapid metabolizer (1-3\% of white population) is someone that has multiple copies of the CYP2D6 gene, and therefore greater CYP2D6 function. Ultrarapid metabolizers may have very low plasma levels of certain drugs and treatment successful may be jeopardized in these patients. Extensive metabolizers have normal CYP2D6 function and metabolize drugs at a normal rate while intermediate metabolizers process drugs at a rate somewhere between the poor and extensive metabolizers.

Many CYP's are sensitive to induction by xenobiotics (external chemical compounds, including drugs). For instance, metabolism of CYP1A2 is elevated in smokers. As a result, smokers may respond differently than nonsmokers to a psychoactive drug that is metabolized as a CYP1A2 substrate.

Age is another factor that can also influence CYP levels in liver, brain and other tissues. For example, the CYP2D6 in the brain is low at birth, increases gradually with age, and is highest in the elderly. In contrast, CYP2D6 hepatic level increases quickly after birth to adult levels and remains constant thereafter. This implies that for some CNS acting drugs, the elderly may respond differently than younger adults. These differences may contribute to the fact that individual elderly patients respond in a different way than younger patients to drugs that are inactivated by CYP2D6 like desipramine $[3,32,33]$.

\section{Antipsychotics and CYP isozymes}

CYP-related drug interactions are usually derived from either enzyme inhibition or enzyme induction. CYP isozymes clinically relevant for antipsychotics are well characterized at the molecular level and their principal substrates have been recognized. Most of the main inhibitors and inducers have also been identified.

Inhibition of an enzyme typically implies competition with another drug for the enzyme binding site. Therefore, the rate of metabolism of a drug is reduced, which results in greater plasma levels and potentially leads to an augmentation of its pharmacologic effects. Many compounds may inhibit the activity of more than one CYP isozym [7,29,34,35].

Competitive inhibition is usually dose-dependent. Its effects may appear within hours of ingestion of the inhibitor, although the time to reach maximum inhibition depends on the respective plasma half-life of the drug and on the inhibitor. When the inhibitor is discontinued, return of previous conditions also depends on the time required to metabolize both the drug and the inhibiting agent.

Enzyme induction is a slow biologic process that is not only dose dependent but also time dependent. Enzyme induction may affect the pharmacokinetics of agents metabolized by the enzyme, as it can produce decreased plasma levels of a drug and therefore it can affect its clinical effectiveness. In general, the extent of induction is proportional to the dose of the inducing agent because the process requires synthesis of the new enzyme, but induction effects appear with a delay (in general, from 3 to 14 days) after exposure to the inducing agent. When the inducting agent is withdrawn, the time required for returning to baseline conditions depends on the rate of elimination of both the enzyme and the drug $[3,35]$.

Many antipsychotics are metabolized by CYP isozymes. Understanding the metabolism of antipsychotics by the CYP system can alert the clinician on how to avoid and manage drug-drug 
interactions involving these enzymes. $[6,7,29,34,35]$. Table 2 shows the role of the most commonly used typical and atypical antipsychotics as substrates or inhibitors of main CYP enzymes [7,34,36,37].

The main CYP's isozymes and its potential interactions with some commonly used antipsychotic agents are discussed in detail in the following section

3.5.1 CYP1A2: CYP1A2 constitutes about $13 \%$ of the total CYP content and is mainly a hepatic enzyme that metabolizes chemicals and environmental toxins. CYP1 family is mainly involved in the metabolism of polycyclic aromatic hydrocarbons and halogenated aromatic hydrocarbons. These CYP's have substantial variations in activity due to a variety of modulating factors, such as genetic polymorphism, age, gender, disease status, pharmacotherapy, and dietary factors $[38,39]$.

CYP1A2 has been shown to mainly catalyze the metabolism of polycyclic aromatic hydrocarbons (PAH), which are common components of cigarette smoke. CYP1A2 can activate benzopyrene, a carcinogen present in cigarette smoke, and it is a strong inducer of CYP1A2 since it can increase the synthesis of this isoenzyme by 3 fold. Other drugs metabolized by CYP1A2 include theophylline, warfarin, and several antidepressants and antipsychotics, including clozapine, haloperidol and olanzapine. Substrates and inhibitors for CYP1A2 includes caffeine and cigarette smoke [40-43]. Table 3 shows the major substrates, inhibitors, and inducers of human CYP1A2 [7,17,34,39,41].
3.5. 2 CYP2D6: The CYP2 family is the largest and most diverse of the CYP families and is responsible for the metabolism of a wide variety of compounds. Although CYP2D6 only accounts for up to $2 \%$ of the liver CYP content $[44,45]$, it has an important role in drug metabolism particularly for the clinical use in psychopharmacology. In humans, CYP2D6, is also expressed in various tissues including the kidney, placenta, brain, breast, lung and intestine $[35,46,47]$.

CYP2D6 exhibit genetic polymorphism. CYP2D6 polymorphism has been the most studied human genetic polymorphism in drug metabolism with more than 80 identified alleles within the most diverse human population and ethnic groups. The activity of CYP2D6 shows a bimodal distribution indicating the presence of dominant and recessive alleles in the population. It has been estimated that $7-10 \%$ of Caucasians are poor metabolizers [33,35,47,48].

At the moment, CYP2D6 is not inducible by pharmacological agents and therefore, CYP2D6 is generally regarded as non-inducible. Although quinidine is not a substrate for CYP2D6, it is a strong CYP2D6 inhibitor and therefore widely used in interactions studies [49]. CYP2D6 is the only CYP enzyme not inducible by other drugs. While some drugs such as rifampicin and dexamethasone were found to slightly induce CYP2D6 in humans, this effect is not considered clinically significant $[17,50]$.

More than 80 drugs in clinical use are metabolized by CYP2D6 and most of psychotropic agents are metabolized by this way. Since many antipsychotic are metabolized by CYP2D6, poor metabolizers

The following is an example to illustrate the CYP naming system using CYP3A4:

The standard abbreviation for human cytochrome P450 is CYP.

Families of the isozyme which share greater than $40 \%$ protein sequence homology with each other are designated by the first number following the cytochrome $\mathrm{P} 450$ designation, e.g., 3

Subfamilies which share greater than $60 \%$ homology with each other are differentiated by the letter following the family designation, e.g., A.

Single members of subfamilies represent a particular gene and are designated by the number following the subfamily description, e.g., 4 .

Table 1: The cytochrome P450 nomenclature system [31].

\begin{tabular}{|c|c|c|c|}
\hline Atypical & CYP1A2 & CYP2D6 & CYP3A4 \\
\hline \multicolumn{4}{|l|}{ Amisulpride } \\
\hline Aripiprazole & & Substrate & Substrate \\
\hline Asenapine & Substrate & Inhibitor (weak) & \\
\hline \multicolumn{4}{|l|}{ Clotiapine } \\
\hline Clozapine & Substrate & Substrate & Substrate \\
\hline Olanzapine & Substrate & Substrate & \\
\hline \multicolumn{4}{|l|}{ Paliperidone } \\
\hline Quetiapine & & Substrate & Substrate \\
\hline Risperidone & & Substrate & Substrate \\
\hline \multicolumn{4}{|l|}{ Sulpiride } \\
\hline \multicolumn{4}{|l|}{ Tiapride } \\
\hline Ziprasidone & & & Substrate \\
\hline Typical & CYP1A2 & CYP2D6 & CYP3A4 \\
\hline Chlorpromazine & Substrate & Inhibitor & \\
\hline Fluphenazine & Substrate & Inhibitor & \\
\hline Haloperidol & Substrate & Inhibitor (potent) & Substrate \\
\hline Levomepromazine & & Inhibitor & \\
\hline Perphenazine & & Inhibitor & \\
\hline Pimozide & Substrate & Inhibitor (potent) & Substrate \\
\hline Zuclopenthixol & & Substrate & \\
\hline
\end{tabular}

Green color means that the drug is not metabolized by CYP-related metabolism or the metabolism is not significant clinically. Yellow means that the drug is a substrate of the isoenzyme and red is related to the inhibitory potential of the drug.

Data based on the respective drug labels and the following references: $[7,34,36,37]$.

Table 2: Role of commonly used atypical and typical antipsychotics as substrates or inhibitors of major CYP isozymes. 


\begin{tabular}{|c|c|c|}
\hline Substrates & Inhibitors & Inducers \\
\hline Antipsychotics: & & \\
Asenapine & & \\
Clozapine & & \\
Haloperidol & & \\
Olanzapine & & \\
Chlorpromazine & & \\
Fluphenazine & & \\
Pimozide & & \\
& & \\
Antidepressants: & & \\
Amitriptyline & Fluoxetine & \\
Clomipramine & Fluvoxamine & \\
Duloxetine & Paroxetine & \\
Fluvoxamine & Sertraline & \\
Imipramine & & \\
Mirtazapine & & \\
\hline Others: & & \\
Caffeine & & Cigarrette smoke \\
Diazepam & Amiodarone & Barbiturates \\
Melatonin & Caffeine * & Carbamazepine \\
Phenacetin & Ciprofloxacin & Phenytoin \\
Tacrine & Enoxacin & Rifampicin \\
Theophylline & Ginkgo biloba & Ritonavir \\
R-warfarin & & Griseofulvin \\
Zolpidem & & Omeprazole \\
\hline & & Lansoprazole \\
\hline
\end{tabular}

Table 3: Main substrates and clinically relevant inhibitors or inducers of human CYP1A2.

\begin{tabular}{|c|c|c|}
\hline Substrates & Inhibitors & Inducers \\
\hline $\begin{array}{l}\text { Antipsychotics: } \\
\text { Aripiprazole } \\
\text { Clozapine } \\
\text { Olanzapine } \\
\text { Risperidone } \\
\text { Thioridazine } \\
\text { Pimozide } \\
\text { Quetiapine } \\
\text { Zuclophentixol }\end{array}$ & $\begin{array}{l}\text { Asenapine } \\
\text { Chlorpromazine } \\
\text { Fluphenazine } \\
\text { Levomepromazine } \\
\text { Perphenazin } \\
\text { Haloperidol }\end{array}$ & \\
\hline $\begin{array}{l}\text { Antidepressants: } \\
\text { Mirtazapine } \\
\text { Desvenlafaxine }\end{array}$ & $\begin{array}{l}\text { Bupropion } \\
\text { Duloxetine } \\
\text { Fluoxetine } \\
\text { Paroxetine } \\
\text { Sertraline } \\
\text { Citalopram } \\
\text { Escitalopram } \\
\text { Fluvoxamine } \\
\text { Tricyclics } \\
\text { Venlafaxine }\end{array}$ & \\
\hline $\begin{array}{l}\text { Others: } \\
\text { Antiarrhythmics } \\
\text { Beta blockers } \\
\text { Opioids } \\
\text { Tramadol } \\
\text { Atomoxetine } \\
\text { Donepezil } \\
\text { Galantamine } \\
\text { Phenformin } \\
\text { Melatonin } \\
\text { Methadone }\end{array}$ & $\begin{array}{l}\text { Amiodarone } \\
\text { Lansoprazole } \\
\text { Quinidine } \\
\text { Cocaine } \\
\text { Ritonavir } \\
\text { Valproicacid }\end{array}$ & $\begin{array}{l}\text { Carbamazepine } \\
\text { Dexamethasone } \\
\text { Phenytoin } \\
\text { Rifampicin }\end{array}$ \\
\hline
\end{tabular}

Table 4: Main substrates and clinically relevant inhibitors, and inducers of human CYP2D6. are at risk for ADR like postural hypotension and extrapyramidal side effects $[33,47,48]$. Table 4 shows the principal substrates, inhibitors, and inducers of human CYP1A2 [7,17,34,50].

3.5.3 CYP3A4: CYP3A4 accounts for approximately 30\% of total hepatic content and $70 \%$ of CYP gut wall content. CYP3A4, is involved in metabolism of large number of endogenous and exogenous compounds. Since almost $50 \%$ of drugs are metabolized by CYP3A4 some of the most serious drug interactions have been caused by accumulation of substrates by the influence of inhibitors or inducers [21,51]. Strong inhibitors of CYP3A4 like erythromycin, ketoconazole, itraconazole and grape fruit juice have caused elevated substrate levels that have precipitated prolonged QT interval, torsades de pointes and even death [52]. Grape fruit juice may down-regulate CYP3A4 expression in small intestine which can lead to a higher bioavailability of cyclosporine, terfenadine and triazolam [53,54]. Clarithromycin and erythromycin may decrease drugs metabolism by inhibiting CYP3A4. Rifampicin, carbamazepine, barbiturates and phenytoin are potent inducers of CYP3A4 [22].

Inhibitors and inducers of CYP3A4 may affect the metabolism of antipsychotics that are CYP3A4 substrates like quetiapine. Quetiapine pharmacokinetics is strongly affected by concomitant administration of clarithromycin, ketoconazole and carbamazepine. Other drugs that modulate the activity or expression of CYP3A4 would also affect the exposure to quetiapine [15]. CYP3A4 plays a major role of in hepatic bioactivation of clozapine, which cause hepatotoxicity in a small percentage of patients. Interindividual differences and drug-drug interactions at the level of CYP3A4 might cause changes in exposure of hepatic tissue to reactive clozapine metabolites [46].

CYP3A4 and P-glycoprotein (P-gp) may act together to limit oral drug bioavailability. CYP3A4 and P-gp are an integral part of an intestinal defense system to protect the body against xenobiotics. As a result, drugs that are substrates of both proteins often have a low bioavailability after oral administration. Both proteins are expressed in enterocytes and hepatocytes and contribute to a major extent to firstpass elimination of many drugs. There is an overlapping of substrate specificities and inhibitor/inducers between CYP3A4 and P-gp. Many drug interactions may involve both CYP3A4 and P-gp and often it is difficult to discriminate the specific cause of drug interactions $[19,55,56]$. Table 5 shows the principal substrates, inhibitors, and inducers of human CYP3A4 [7,17,21,34].

\section{Interactions with other substances}

Sometimes the CYP's inducers or inhibitors are commonly consumed substances such grape fruit juice, caffeine and tobacco smoke. In the case of grape fruit juice, there are many drugs known to interact including statins, antiarrhythmic agents, immunosuppressive agents, and calcium channel blockers. The inhibition of the enzyme system seems to be dose dependent; thus, the more a patient drinks grapefruit juice, the more the inhibition that occurs. In addition, the effects can last for several days if grapefruit juice is consumed on a regular basis. This effect has not been reported with other fruit juices $[53,54]$.

Caffeine is a substrate of CYP1A2. When caffeine is ingested, there is less of CYP1A2 available to metabolize other drugs. Thus, caffeine acts as a metabolic inhibitor, slowing down the speed with which the organism can metabolize medications. The result is an increment of plasma level of these drugs, caffeine, or both. [39,41].

Cigarette smoking remains highly prevalent in most countries. 


\begin{tabular}{|c|c|c|}
\hline Substrates & Inhibitors & Inducers \\
\hline $\begin{array}{l}\text { Antipsychotics: } \\
\text { Aripiprazole } \\
\text { Clozapine } \\
\text { Haloperidol } \\
\text { Risperidone } \\
\text { Quetiapine } \\
\text { Sertindole } \\
\text { Ziprasidone } \\
\text { Pimozide }\end{array}$ & & \\
\hline $\begin{array}{l}\text { Antidepressants: } \\
\text { Tricyclics } \\
\text { Citalopram } \\
\text { Escitalopram } \\
\text { Mirtazapine } \\
\text { Venlafaxine } \\
\text { Desvenlafaxine }\end{array}$ & $\begin{array}{l}\text { Fluoxetine } \\
\text { Fluvoxamine } \\
\text { Paroxetine } \\
\text { Sertraline }\end{array}$ & \\
\hline $\begin{array}{c}\text { Others: } \\
\text { Benzodiazepines } \\
\text { Caffeine } \\
\text { Calcium channel } \\
\text { antagonists } \\
\text { Cocaine } \\
\text { Statins } \\
\text { Astemizole } \\
\text { Cisapride } \\
\text { Cyclosporine } \\
\text { Sirolimus } \\
\text { Tacrolimus } \\
\text { Donepezil } \\
\text { Ethinyl estradiol } \\
\text { Levonorgestrel } \\
\text { Quinidine } \\
\text { Tamoxifen } \\
\text { Terfenadine } \\
\text { Tramadol } \\
\text { Fentanyl } \\
\text { Omeprazole } \\
\text { Lansoprazole } \\
\text { Warfarin }\end{array}$ & $\begin{array}{l}\text { Amiodarone } \\
\text { Atazanavir } \\
\text { Boceprevir } \\
\text { Ciprofloxacin } \\
\text { Clarithromycin } \\
\text { Cyclosporine } \\
\text { Darunavir } \\
\text { Erythromycin } \\
\text { Gingko-biloba } \\
\text { Grapefruit juice } \\
\text { Indinavir } \\
\text { Itraconazole } \\
\text { Ketoconazole } \\
\text { Lopinavir } \\
\text { Methadone } \\
\text { Nefazodone } \\
\text { Ritonavir } \\
\text { Telaprevir } \\
\text { Troleandomycin } \\
\text { Valproic acid }\end{array}$ & $\begin{array}{c}\text { Barbiturates } \\
\text { Carbamazepine } \\
\text { Dexamethasone } \\
\text { Efavirenz } \\
\text { Etravirine } \\
\text { Glucocorticoids } \\
\text { Melatonin } \\
\text { Nevirapine } \\
\text { Phenytoin } \\
\text { Prednisone } \\
\text { Rifampicin } \\
\text { Ritonavir } \\
\text { St John's wort } \\
\text { Topiramate }\end{array}$ \\
\hline
\end{tabular}

Table 5: Main substrates and clinically relevant inhibitors, and inducers of human CYP3A4.

Many psychiatric patients smoke, and are believed to be heavier smokers than those without psychiatric disorders. Cigarette smoking is one of the environmental factors that contribute to interindividual variations in response to an administered drug. It can affect drug therapy by both pharmacokinetic and pharmacodynamic mechanisms. Polycyclic aromatic hydrocarbons (PAH) in tobacco smoke are believed to be responsible for the induction of CYP1A1 and CYP1A2 $[16,40]$. Clinicians must also be aware of the potential impact of stopping cigarette smoking on the metabolism of some psychoactive drugs, for example, clozapine and olanzapine [46]. Blood levels of these antipsychotics may be reduced as the hydrocarbons in cigarette smoke no longer induce the CYP system and blood levels of the affected drugs could increase to high levels. According to the last National Institute for Health and Care Excellence [43] Guideline on Psychosis and Schizophrenia in Adults, the effect of smoking on patients receiving clozapine is of particular concern and should be considered in advance of smoking cessation.

\section{Polypharmacy}

Drug-drug interactions constitute a main challenge in clinical practice, especially in elderly and other polymedicated patients. Polypharmacy has been associated with increased adverse drug reactions, hospitalization and mortality $[57,58]$.

Loya et al. [32] conducted a study about prevalence of polypharmacy, use of herbal products, nutritional supplement and potential product interactions among older adults in the United States. In this descriptive study, 130 participants with a mean age of 71.4 years were recruited. The prevalence of polypharmacy among all participants was $72.3 \%(\mathrm{n}=94)$. In addition, 21 participants $(16.2 \%)$ reported that they were two or more herbal products (polyherbacy). Assessment of potential interactions showed that $46.2 \%(n=60)$ of participants were at risk of having at least one potential drug-drug interaction. Regarding drug and herbal product or supplement interactions, $31.5 \%(n=41)$ of participants were at risk of having at least one possible interaction. According the authors, almost half of the older adults communitydwelling were at risk for a potential drug-drug interaction, while approximately one-third were at risk for potential interaction between their prescription drugs, herbal products or nutraceutical supplements.

Even in an apparently healthy population, polypharmacy is an important concern for patient safety. Husson et al. [58] conducted a survey to assess the main characteristics associated with polypharmacy in 2,545 volunteers ( 1,175 women, and 1,370 men) aged $66( \pm 4.8)$ years. In this study, polypharmacy was defined as the concomitant use of 4 or more drugs. Investigators found that the prevalence of polypharmacy was $29.9 \%$ in apparently healthy people aged 60 years and over.

A study of drug interactions among recently hospitalized patients $(n=200)$ was conducted in Denmark, including, 83 surgical and 117 medical patients. The median age of the population included was 75 years and $70 \%$ were women. In this survey, patients stored 2119 medications at home (median: 9 per patient) and used 1622 medications daily or on demand (median: 8 per patient). In total, 476 potential interactions were identified in 126 patients ( $63 \%$ of patients), showing that there is a high potential of drug interactions, especially in elderly and other polymedicated patients [59]. In consequence, it is advisable that clinicians consider the risks associated to polypharmacy before issuing any prescriptions in elderly people to avoid drug-drug interactions. Usual strategies to avoid polypharmacy complications include dose adjustment or changing for another drug less or not susceptible to drug-drug interactions.

\section{Clinical interactions in psychiatry}

In psychiatry, the range of psychotropic agents has increased enormously over the last 2 decades and it implies that drug interactions have expanded as well $[50,60]$. In a recent retrospective review of hospitalized psychiatric patients, medication classes responsible for adverse drug reactions (ADRs) included mood stabilizers (30\%), typical antipsychotics (25\%), atypical antipsychotics (25\%), and antidepressants (8\%), and most of these ADRs were due to a drug-drug interaction [2].

The clinical effect a psychoactive drug has on a given patient may be different than expected because the drug interacts with another drug (drug-drug interaction) or with substances of common use, misuse or abuse (caffeine, nicotine, alcohol, and illegal substances). Food, beverages, vitamins, and supplements can also interact with drugs (food-drug or nutrient-drug interactions) [61-63].

Concomitant prescription of two or more antipsychotics is an increasingly common practice in psychiatry. This clinical practice does not reflect clinical guidelines recommendations that promote 
antipsychotic monotherapy. A common reason for prescribing more than one antipsychotic is to gain a greater or more rapid therapeutic response than has been achieved with monotherapy. Surveys of prescribing in psychiatric centers have identified the relatively frequent and consistent use of combined antipsychotics, frequently for patients with schizophrenia, with a prevalence of around $50 \%$ in certain clinical settings $[9,63,64]$.

The relatively widespread use of antipsychotic polypharmacy identified in clinical surveys reflects not only the addition of a second antipsychotic to improve therapeutic response, but also the use on demand of antipsychotic medication, especially to treat behavior disturbances. The evidence on the risks and benefits for such a strategy is not clear. Nevertheless, the most reasonable strategy seems to consider the pharmacodynamic and pharmacokinetic properties of the combined agents $[63,65,66]$.

\section{Potential interactions with antipsychotic agents}

Clinical interactions are common with antipsychotic drugs. Most commonly used antipsychotic are metabolized through CYP's hepatic pathways and this is the cause of frequent interactions. Some antipsychotic agents, like amilsupride and paliperidone, have a negligible hepatic biotransformation, and therefore are unlikely to be involved in clinically significant drug-drug interactions [67-70].

The metabolism and potential interactions of the main antipsychotic agents are discussed in detail in the following section $[6,34,70]$.

Clozapine: Clozapine was the first second-generation antipsychotic released for clinical use. Therefore, there are more data available on its metabolism than on other medications in this class. Clozapine is primarily metabolized by CYP1A2 with many secondary pathways. It seems well established that CYP1A2 is involved in the metabolism of clozapine. Clozapine appears to be an in vitro P-glycoprotein substrate and it is also a mild inhibitor of 2D6. Clozapine has a low therapeutic index $[38,46]$.

Fluvoxamine, a selective serotonin reuptake inhibitor (SSRI), inhibits CYP1A2, and can cause a strong inhibition of clozapine metabolism. Increased serum levels of clozapine after the start of fluvoxamine treatment have been reported from several cases $[7,39]$.

There is evidence that interactions between clozapine and caffeine may be clinically relevant. It has been described that individuals being treated with clozapine showed signs of increased arousal and extrapyramidal symptoms after consuming caffeinated beverages. Usually, the signs and symptoms resolved when non-caffeinated drinks were substituted $[39,41]$.

Cigarette smoking induces CYP1A2. Smokers have been observed to have lower serum levels of clozapine than nonsmokers, sometimes significantly lower. This interaction may be clinically relevant and must be take on account also when the patient is considering to stop smoking $[40,42,43]$.

Risperidone: Compared to other commonly used antipsychotic agents, many publications have reported potential DDIs involving risperidone. Risperidone is mainly metabolized by through CYP2D6, and to a lesser extent by CYP 3A4. In vitro studies have shown that CYP2D6 catalyzes the metabolism of risperidone to its major active metabolite, 9-hydroxyrisperidone (paliperidone). Risperidone is also an in vitro P-glycoprotein substrate of moderate to strong affinity, and acts as a mild to moderate 2D6 inhibitor $[3,6,34]$.

Olanzapine: The role of CYP's in the metabolism of olanzapine has become clearer in recent years. Olanzapine is mostly metabolized by CYP1A2, with CYP2D6 and UGT serving as minor pathways. Olanzapine is also a P-glycoprotein substrate of low to moderate affinity and acts as a P-glycoprotein inhibitor.

CYP1A2 is responsible for the formation of N-desmethylolanzapine and the formation of this metabolite correlated significantly with olanzapine clearance rates in vitro. Concomitant treatment with the CYP1A2 inhibitor fluvoxamine resulted in increased serum levels and decreased rates of clearance of olanzapine, along with decreased serum levels of N-desmethyl-olanzapine [7].

The polycyclic aromatic hydrocarbons contained in cigarette smoke are strong inducers of CYP1A2. Smokers have been observed to have changes in serum levels of olanzapine. This interaction may be clinically relevant $[40,42,43]$.

Quetiapine: Quetiapine is primarily metabolized by CYP3A4. It is also a P-glycoprotein substrate of moderate to strong affinity and acts as a P-glycoprotein inhibitor. In a dosing study, concomitant administration of the CYP3A4 inhibitor ketoconazole resulted in a significant increase in serum quetiapine levels and its half-life. Concomitant administration of the CYP inducer phenytoin resulted in a significant decrease in serum quetiapine levels that corresponded with an increase in clearance rates. Since quetiapine is primarily metabolized by CYP3A4, the observed pharmacokinetic changes are due to induction of CYP3A $[15,21,22,51]$.

Ziprasidone: Ziprasidone is principally metabolized by aldehyde oxidase, with CYP3A4 serving as a secondary pathway. In vitro data indicate that CYP3A4 is the primary CYP involved in the metabolism of ziprasidone. Concomitant administration of CYP3A4 inhibitors altered the drug's pharmacokinetics. A significant increase in serum levels of ziprasidone was observed when the drug was administered along with ketoconazole $[15,22,34]$.

Haloperidol: The metabolism of haloperidol is fairly complex. It is based mostly on CYP3A4 activity, with secondary contributions from 2D6 and 1A2, and other phase II reactions. Haloperidol appears to be a P-glycoprotein substrate of weak affinity. Some of haloperidol's metabolites are also inhibitors of 2D6. Haloperidol is also a P-glycoprotein inhibitor. Haloperidol may increase anticholinergic and also may increase CNS depressant effects of anesthetics, opiates, and alcohol. A total of 972 drugs are known to interact with haloperidol $[3,6,34]$.

Paliperidone: Paliperidone, or 9-hydroxy-risperidone, is the major active metabolite of risperidone. Due to its negligible hepatic biotransformation, paliperidone is unlikely to be involved in clinically significant metabolic interactions. In pharmacokinetic studies no metabolites could be detected in plasma. Renal excretion is the major route of elimination with $59 \%$ of the dose excreted unchanged in urine. Other four minor metabolic pathways were identified, each of which accounted for up to a maximum of $6.5 \%$ of the administered dose. There are additional properties in terms of its lower protein binding and decreased inhibition of P-glycoprotein that lead to a decreased potential for drug-drug interactions $[67,68,70]$.

Aripiprazole: Metabolism of aripiprazole is approximately equally divided between CYP2D6 and CYP3A4. It doesn't have any known inhibitory or inductive properties of clinical relevance [9,34].

\section{Avoiding interactions with antipsychotic agents}

In order to prevent drug interactions with antipsychotic agents 
clinicians have to be particularly alert to drugs with a narrow therapeutic index or drugs that require a strictly stable serum concentrations such as anticoagulants, anticonvulsants, anti-infectives, cardiovascular therapeutics, oral contraceptives, glucocorticoids, immunosuppressants, sulphonylureas, theophyllines, antiretroviral agents and other psychotropics. In addition, clinicians should remember some well-known inducers or inhibitors of CYP system, like rifampicin, ciprofloxacin, fluvoxamine, barbiturates, carbamazepine, phenytoin, and warfarin among others $[6,34,64]$.

It is important for clinicians to stay alert when treating psychiatric patients with difficult comorbidities requiring polypharmacy, especially in elderly or in patients with reduced hepatic or renal function. Physicians must take into account that polypharmacy, comorbidity and the use of certain substances (grapefruit juice, caffeine, tobacco, alcohol) is the basic scenario for the development of clinically relevant interactions in a psychotic patient.

The best approach to prevent clinical interactions is to be aware that they can occur. The choice of drugs with a pharmacokinetic profile with low potential for clinically relevant interactions is the most reasonable strategy for many psychiatric patients, especially for the elderly and polymedicated patients $[4,57,68,71]$.

\section{Conclusions}

System may play a critical role in the magnitude and duration of the effects of drugs, either for their catabolic properties inactive metabolites or for the bioactivation of prodrugs to active drugs. These isoenzymes may also be involved in the development of reactive metabolites which can be allergenic, toxic or mutagenic.

The CYP's isoenzymes are all inducible except CYP2D6. The genes encoding CYP2A6, CYP2C9, CYP2C19 and CYP2D6 are functionally polymorphic. In the case of CYP1A2 and CYP3A4, there are known polymorphisms, primarily in their regulatory regions, although its functional significance is not yet fully elucidated.

Drug-drug interactions are closely related to CYP system activity and are responsible for substantial patient morbidity. Drug-drug interactions are responsible for approximately $20 \%$ to $30 \%$ of adverse reactions. The risk for DDIs increases substantially when the number of concomitants drugs increase. Cigarette smoke, alcohol, caffeine and some nutrients are other factors that increase the risk of interactions. It must be highlighted that some food like cauliflower, broccoli or grilled meat, have the potential to be CYP450 inducers. As they can induce CYP1A2, they could interact with antipsychotics that are metabolized by the same isoenzyme, such as clozapine or olanzapine. These factors, added to a great variability of CYP system activity between individuals suggest that drug interactions are not always easy to recognize.

The knowledge of the metabolism of second generation antipsychotics by CYP's can alert the physician about how to prevent and manage drug-drug interactions involving these enzymes.

Clozapine is metabolized primarily by CYP1A2, with additional contributions by CYP2C19, CYP2D6 and CYP3A4. Risperidone is metabolized primarily by CYP2D6 and to a lesser extent by CYP3A4. In contrast to the case of risperidone, the metabolism of paliperidone (9-hydroxy-risperidone) in the liver is very limited. Olanzapine is metabolized primarily by CYP1A2 and to a lesser extent by CYP2D6. Quetiapine and ziprasidone are metabolized by CYP3A4 [72].

The concomitant prescription of more than one antipsychotic is an increasingly common practice in clinical psychiatry. DDIs are some of the most common causes of morbidity related to the use of medication, particularly in aging patients due to polytherapy. For that reason, the choice of a drug with no or minimal potential of interactions is a reasonable approach in clinical psychiatry [73].

Since many antipsychotics are metabolized by CYP isozymes, there are some practical principles to prevent and resolve drug interactions. Clinicians must be alert to drugs with a low therapeutic index or that required a strictly stable serum concentration. Clinicians should also be vigilant when psychotropics are prescribed concurrently with other medications. Close monitoring of plasma drug levels should be carried out to assure efficacy and to avoid toxicity. In addition, they should remember the most well-known inducers or inhibitors of CYP system.

It is important for clinicians to be alert when treating psychiatric patients with difficult comorbidities requiring polypharmacy, especially in elderly or patients with reduced hepatic or renal function. Physicians must take into account that polypharmacy, comorbidity and the use of certain substances (grape fruit juice, caffeine, tobacco) improves the chances for clinically relevant interactions in a psychotic patient.

In summary, the choices of psychotropic drugs (for example, antipsychotics like paliperidone or amisulpride) that virtually do not interfere with the hepatic metabolism via the CYP'ssystem represent an alternative therapeutic approach for those patients with polypharmacy. Thus, the chance of having undesirable drug-drug interactions, mainly in those patients in whom it is essential to ensure stable therapeutic concentrations, are reduced, for example, in patients treated for substance abuse, cancer patients or HIV seropositive patients.

\section{Acknowledgement}

Editorial assistance was provided by Content Ed Net, Madrid, Spain, with funding from Janssen.

\section{References}

1. Yap KY, Chan A, Chui WK, Chen YZ (2010) Cancer informatics for the clinician: an interaction database for chemotherapy regimens and antiepileptic drugs. Seizure 19: 59-67.

2. luppa CA, Nelson LA, Elliott E, Sommi RW (2013) Adverse drug reactions: a retrospective review of hospitalized patients at a state psychiatric hospital Hosp Pharm 48: 931-935.

3. Baxter, Karen and Preston, Claire L (2008) Stockley's Drug Interactions A source book of interactions, their mechanisms, clinical importance and management (10thedn.) Pharmaceutical Press.

4. Yap KY, Tay W, Chui WK, Chan A (2011) Clinically relevant drug interactions between anticancer drugs and psychotropic agents. Eur J Cancer Care (Engl) 20: 6-32.

5. Spatzenegger M, Jaeger W (1995) Clinical importance of hepatic cytochrome P450 in drug metabolism. Drug Metab Rev 27: 397-417.

6. Prior TI, Baker GB (2003) Interactions between the cytochrome P450 system and the second-generation antipsychotics. J Psychiatry Neurosci 28: 99-112.

7. Spina E, Santoro V, D'Arrigo C (2008) Clinically relevant pharmacokinetic drug interactions with second-generation antidepressants: an update. Clin Ther 30 1206-1227.

8. Wilcock A, Thomas J, Frisby J, Webster M, Keeley V, et al. (2005) Potential for drug interactions involving cytochrome $\mathrm{P} 450$ in patients attending palliative day care centres: a multicentre audit. Br J Clin Pharmacol 60: 326-329.

9. Urichuk L, Prior TI, Dursun S, Baker G (2008) Metabolism of atypical antipsychotics: involvement of cytochrome p450 enzymes and relevance for drug-drug interactions. Curr Drug Metab 9: 410-418.

10. Bleakley S (2012) Identifying and reducing the risk of antipsychotic drug interactions. Progress in Neurology and Psychiatry16: 20-24.

11. Demler TL (2012) Psychiatric Drug-Drug Interactions. A Refresher US Pharmacist 37: 16-19. 
12. Alper K, Schwartz KA, Kolts RL, Khan A (2007) Seizure incidence in psychopharmacological clinical trials: an analysis of Food and Drug Administration (FDA) summary basis of approval reports. Biol Psychiatry 62: 345-354

13. Spina E, de Leon J (2014) Clinically relevant interactions between newer antidepressants and second-generation antipsychotics. Expert Opin Drug Metab Toxicol 10: 721-746.

14. Armahizer MJ, Seybert AL, Smithburger PL, Kane-Gill SL (2013) Drug-drug interactions contributing to QT prolongation in cardiac intensive care units. $J$ Crit Care 28: 243-249.

15. Grimm SW, Richtand NM, Winter HR, Stams KR, Reele SB (2006) Effects of cytochrome P450 $3 \mathrm{~A}$ modulators ketoconazole and carbamazepine on quetiapine pharmacokinetics. Br J Clin Pharmacol 61: 58-69.

16. Kroon LA (2007) Drug interactions with smoking. Am J Health Syst Pharm 64: 1917-1921.

17. Miksys S, Tyndale RF (2013) Cytochrome P450-mediated drug metabolism in the brain. J Psychiatry Neurosci 38: 152-163.

18. Knights KM, Rowland A, Miners JO (2013) Renal drug metabolism in humans: the potential for drug-endobiotic interactions involving cytochrome P450 (CYP) and UDP-glucuronosyltransferase (UGT). Br J Clin Pharmacol 76: 587-602.

19. Baron JM, Goh LB, Yao D, Wolf CR, Friedberg T (2001) Modulation of P450 CYP3A4-dependent metabolism by P-glycoprotein: implications for P450 phenotyping. J Pharmacol Exp Ther 296: 351-358.

20. Lemahieu WP, Maes BD, Verbeke K, Vanrenterghem Y (2004) CYP3A4 and $P$-glycoprotein activity in healthy controls and transplant patients on cyclosporin vs. tacrolimus vs. sirolimus. Am J Transplant 4: 1514-1522.

21. Kato M, Chiba K, Ito T, Koue T, Sugiyama $Y$ (2010) Prediction of interindividual variability in pharmacokinetics for CYP3A4 substrates in humans. Drug Metab Pharmacokinet 25: 367-378.

22. Sekimoto M, Sano S, Hosaka T, Nemoto K, Degawa M (2012) Establishment of a stable human cell line, HPL-A3, for use in reporter gene assays of cytochrome P450 3A inducers. Biol Pharm Bull 35: 677-685.

23. Chen X, Wang H, Zhou G, Zhang X, Dong X, (2009) Molecular population genetics of human CYP3A locus: signatures of positive selection and implications for evolutionary environmental medicine. Environ Health Perspect 117: 1541-1548.

24. Zanger UM, Schwab M (2013) Cytochrome P450 enzymes in drug metabolism: regulation of gene expression, enzyme activities, and impact of genetic variation. Pharmacol Ther 138: 103-141.

25. Nebert DW, Wikvall K, Miller WL (2013) Human cytochromes P450 in health and disease. Philos Trans R Soc Lond B Biol Sci 368: 20120431.

26. Nelson DR, Koymans L, Kamataki T, Stegeman JJ, Feyereisen R, et al. (1996) P450 superfamily: update on new sequences, gene mapping, accession numbers and nomenclature. Pharmacogenetics 6: 1-42.

27. Sladek NE, Mannering GJ (1966) Evidence for a new P-450 hemoprotein in hepatic microsomes from methylcholanthrene treated rats. Biochem Biophys Res Commun 24: 668-674.

28. Estabrook RW (2003) A passion for P450s (rememberances of the early history of research on cytochrome P450). Drug Metab Dispos 31: 1461-1473.

29. Omura T (2011) Recollection of the early years of the research on cytochrome P450. Proc Jpn Acad Ser B Phys Biol Sci 87: 617-640.

30. Sadee W (2012) The relevance of "missing heritability “ in pharmacogenomics. Clin Pharmacol Ther 92: 428-430.

31. Sim SC, Ingelman-Sundberg M (2013) Update on allele nomenclature for human cytochromes P450 and the Human Cytochrome P450 Allele (CYPallele) Nomenclature Database. Methods Mol Biol 987: 251-259.

32. Loya AM, González-SA, Rivera JO (2009) Prevalence of polypharmacy, polyherbacy, nutritional supplement use and potential product interactions among older adults living on the United States-Mexico border: a descriptive, questionnaire-based study. Drugs Aging 26: 423-436.

33. Peñas-Lledó EM, Llerena A (2013) CYP2D6 genetic polymorphism and psychiatry patients' hospitalization period. Biomark Med 7: 915-916.

34. Sandson NB, Armstrong SC, Cozza KL (2005) An overview of psychotropic drug-drug interactions. Psychosomatics 46: 464-494.
35. Villagra D, Goethe J, Schwartz HI, Szarek B, Kocherla M, et al. (2011) Nove drug metabolism indices for pharmacogenetic functional status based on combinatory genotyping of CYP2C9, CYP2C19 and CYP2D6 genes. Biomark Med 5: 427-438.

36. Vallejo J et al. Tratado de Psiquiatría. Editorial Ars Médica. Cuenca Fernández E et al. Capítulo 118, Interacciones farmacológicas.

37. Desta Z, Kerbusch T, Soukhova N, Richard E, Ko JW, et al. (1998) Identification and characterization of human cytochrome P450 isoforms interacting with pimozide. J Pharmacol Exp Ther 285: 428-437.

38. Vrzal R, Stejskalova L, Monostory K, Maurel P, Bachleda P, et al. (2009) Dexamethasone controls aryl hydrocarbon receptor (AhR)-mediated CYP1A1 and CYP1A2 expression and activity in primary cultures of human hepatocytes. Chem Biol Interact 179: 288-296.

39. Womack CJ, Saunders MJ, Bechtel MK, Bolton DJ, Martin M, et al. (2012) The influence of a CYP1A2 polymorphism on the ergogenic effects of caffeine. $\mathrm{J}$ Int Soc Sports Nutr 9: 7.

40. Desai HD, Seabolt J, Jann MW (2001) Smoking in patients receiving psychotropic medications: a pharmacokinetic perspective. CNS Drugs 15: 469494.

41. Josse AR, Da Costa LA, Campos H, El-Sohemy A (2012) Associations between polymorphisms in the AHR and CYP1A1-CYP1A2 gene regions and habitual caffeine consumption. Am J Clin Nutr 96: 665-671.

42. Muscat JE, Pittman B, Kleinman W, Lazarus P, Stellman SD, et al. (2008) Comparison of CYP1A2 and NAT2 phenotypes between black and white smokers. Biochem Pharmacol 76: 929-937.

43. NICE (2014) Psychosis and Schizophrenia in adults. The NICE Guideline on treatment and management - Updated edition 2014. National Institute for Health and Care Excellence, London, UK.

44. Stevens JC, Marsh SA, Zaya MJ, Regina KJ, Divakaran K, et al. (2008) Developmental changes in human liver CYP2D6 expression. Drug Metab Dispos 36: 1587-1593.

45. Shimada T, Yamazaki H, Mimura M, Inui Y, Guengerich FP (1994) Interindividual variations in human liver cytochrome P-450 enzymes involved in the oxidation of drugs, carcinogens and toxic chemicals: studies with liver microsomes of 30 Japanese and 30 Caucasians. J of Pharmacol Exp Ther 270: 414-423.

46. Dragovic S, Gunness $P$, Ingelman-Sundberg M, Vermeulen NP, Commandeu JN (2013) Characterization of human cytochrome P450s involved in the bioactivation of clozapine. Drug Metab Dispos 41: 651-658.

47. Hicks JK, Swen JJ, Thorn CF, Sangkuhl K, Kharasch ED, et al. (2013) Clinica Pharmacogenetics Implementation Consortium guideline for CYP2D6 and CYP2C19 genotypes and dosing of tricyclic antidepressants. Clin Pharmacol Ther 93: 402-408.

48. Crews KR, Gaedigk A, Dunnenberger HM, Leeder JS, Klein TE, et al. (2014) Clinical Pharmacogenetics Implementation Consortium Guidelines for Cytochrome P450 2D6 Genotype and Codeine Therapy: 2014 Update. Clin Pharmacol Ther 95: 376-382.

49. Pelkonen O, Turpeinen M, Hakkola J, Honkakoski P, Hukkanen J, et al. (2008) Inhibition and induction of human cytochrome P450 enzymes: current status. Arch Toxicol 82: 667-715.

50. Anna Haduch A, Bromek E, Daniel WA (2013) Role of brain cytochrome P450 (CYP2D) in the metabolism of monoaminergic neurotransmitters. Pharmacol Rep 65: 1519-1528.

51. Sekiguchi N, Higashida A, Kato M, Nabuchi Y, Mitsui T, et al. (2009) Prediction of drug-drug interactions based on time-dependent inhibition from high throughput screening of cytochrome P450 3A4 inhibition. Drug Metab Pharmacokinet 24: 500-510.

52. Neuvonen PJ (2012) Towards safer and more predictable drug treatmentreflections from studies of the First BCPT Prize awardee. Basic Clin Pharmacol Toxicol 110: 207-218.

53. Bailey DG, Dresser G, Arnold JM (2013) Grapefruit-medication interactions: forbidden fruit or avoidable consequences? CMAJ 185: 309-316.

54. Bressler R (2006) Grapefruit juice and drug interactions. Exploring mechanisms of this interaction and potential toxicity for certain drugs. Geriatrics 61: 12-18.

55. Deenen MJ, Cats A, Beijnen JH, Schellens JH (2011) Part 2: pharmacogenetic variability in drug transport and phase I anticancer drug metabolism. Oncologist 16: 820-834. 
Citation: Mora F, Molina JD, Zubillaga E, López-Muñoz F, Álamo C (2015) CYP450 and Its Implications in the Clinical Use of Antipsychotic Drugs. Clin Exp Pharmacol 5: 176. doi:10.4172/2161-1459.1000176

56. Gavhane YN, Yadav AV (2012) Loss of orally administered drugs in GI tract. Saudi Pharm J 20: 331-344.

57. Girre V, Arkoub H, Puts MT, Vantelon C, Blanchard F, et al. (2011) Potential drug interactions in elderly cancer patients. Crit Rev Oncol Hematol 78: 220226.

58. Husson N, Watfa G, Laurain MC, Perret-GC, Niemier JY, et al. (2014) Characteristics of polymedicated $(\geq 4)$ elderly: a survey in a community-dwelling population aged 60 years and over. J Nutr Health Aging 18: 87-91.

59. Glintborg B, Andersen SE, Dalhoff K (2005) Drug-drug interactions among recently hospitalised patients--frequent but mostly clinically insignificant. Eur J Clin Pharmacol 61:675-681.

60. Stahl SM (1999) Antipsychotic polypharmacy, Part 1: Therapeutic option or dirty little secret? J Clin Psychiatry 60: 425-426.

61. Bernardo M, Coma A, Ibáñez C, Zara C, Bari JM, et al. (2012) Antipsychotic polypharmacy in a regional health service: a population-based study. BMC Psychiatry 12: 42.

62. Gallego JA, Nielsen J, De Hert M, Kane JM, Correll CU (2012) Safety and tolerability of antipsychotic polypharmacy. Expert Opin Drug Saf 11: 527-542.

63. Stahl SM (2013) Emerging guidelines for the use of antipsychotic polypharmacy. Rev Psiquiatr Salud Ment 6: 97-100.

64. Spina E, de Leon J (2007) Metabolic drug interactions with newer antipsychotics: a comparative review. Basic Clin Pharmacol Toxicol 100: 4-22.

65. Lerma-Carrillo I, de Pablo Brühlmann S, del Pozo ML, Pascual-Pinazo F, Molina JD, et al. (2008) Antipsychotic polypharmacy in patients with schizophrenia in a brief hospitalization unit. Clin Neuropharmacol 31: 319-332.
66. Tranulis C, Skalli L, Lalonde P, Nicole L, Stip E (2008) Benefits and risks of antipsychotic polypharmacy: an evidence-based review of the literature. Drug Saf 31: 7-20.

67. Berwaerts J, Cleton A, Herben V, van de Vliet I, Chang I, et al. (2009) The effects of paroxetine on the pharmacokinetics of paliperidone extended-release tablets. Pharmacopsychiatry 42: 158-163.

68. Jones MP, Nicholl D, Trakas K (2010) Efficacy and tolerability of paliperidone ER and other oral atypical antipsychotics in schizophrenia. Int J Clin Pharmaco Ther 48: 383-399.

69. Spina E, Cavallaro R (2007) The pharmacology and safety of paliperidone extended-release in the treatment of schizophrenia. Expert Opin Drug Saf 6: 651-662.

70. Vermeir M, Naessens I, Remmerie B, Mannens G, Hendrickx J, et al. (2008) Absorption, metabolism, and excretion of paliperidone, a new monoaminergic antagonist, in humans. Drug Metab Dispos 36: 769-779.

71. Palleria C, Di Paolo A, Giofrè C, Caglioti C, Leuzzi G, et al. (2013) Pharmacokinetic drug-drug interaction and their implication in clinical management. J Res Med Sci 18: 601-610.

72. Mulder $\mathrm{H}$, Heerdink ER, van lersel EE, Wilmink FW, Egberts AC (2007) Prevalence of patients using drugs metabolized by cytochrome P450 2D6 in different populations: a cross-sectional study. Ann Pharmacother 41: 408-413.

73. Rodríguez-AC, Gurwitz D, de Leon J, Llerena A, Kirchheiner J(2009) CYP2D6 genotyping for psychiatric patients treated with risperidone: considerations for cost-effectiveness studies. Pharmacogenomics. 10: 685-699. 